\title{
Bud-burst modelling in Siberia and its impact on quantifying the carbon budget
}

Ghislain Picard ${ }^{1}$, Shaun Quegan ${ }^{1}$, Nicolas Delbart ${ }^{2}$, Mark R. Lomas ${ }^{1}$, Thuy Le Toan ${ }^{2}$ and F. Ian Woodward ${ }^{1}$

1 .

Centre for Terrestrial Carbon Dynamics

University of Sheffield

Hicks Building

S3 7RH Sheffield, UK

Email: g.picard@sheffield.ac.uk s.quegan@sheffield.ac.uk m.r.lomas@sheffield.ac.uk

f.i.woodward@sheffield.ac.uk

2.

Centre d'Etude Spatiales de la Biosphere

18 av Edouard Belin

BPI 2801

31401 Toulouse cedex 9, France

Email: Nicolas.delbart@cesbio.cnes.fr thuy.letoan@cesbio.cnes.fr

KEY WORDS: phenology, carbon flux, Earth observation, vegetation modelling, NDWI, budburst, climate change, boreal region, Siberia, uncertainties.

Contact:

G. Picard

LGGE

54 rue Moliere

38400 St Martin d'Heres

ghislain.picard@lgge.obs.ujf-grenoble.fr 


\title{
Bud-burst modelling in Siberia and its impact on quantifying the carbon budget
}

\begin{abstract}
Vegetation phenology is affected by climate change and in turn feeds back on climate by affecting the annual carbon uptake by vegetation. To quantify the impact of phenology on terrestrial carbon fluxes, we calibrate a bud-burst model and embed it in the Sheffield Dynamic Global Vegetation Model (SDGVM) in order to perform carbon budget calculations.

Bud-burst dates derived from the VEGETATION sensor onboard the SPOT-4 satellite are used to calibrate a range of bud-burst models. This dataset has been recently developed using a new methodology based on the Normalised Difference Water Index (NDWI), which is able to distinguish snowmelt from the onset of vegetation activity after winter. After calibration, a simple spring warming model was found to perform as well as more complex models accounting for a chilling requirement, hence was used for the carbon flux calculations. The root mean square difference between the calibrated model and the VEGETATION dataset was 6.5 days, and was 6.9 days between the calibrated model and independent ground observations of bud-burst available at 9 locations over Siberia.

The effects of bud-burst model uncertainties on the carbon budget were evaluated using the SDGVM. The 6.5 days RMS difference in the bud-burst date (a 6\% variation in the growing season length), treated as a random noise, translates into about $41 \mathrm{gCm}^{-2}$ year ${ }^{-1}$ in Net Primary Production (NPP), which corresponds to $8 \%$ of the mean NPP. This is a moderate impact and suggests the calibrated model is accurate enough for carbon budget calculations.

In addition to random differences between the calibrated model and VEGETATION data, systematic errors between the calibrated bud-burst model and true ground behaviour may occur, because of bias in the temperature dataset or because the bud-burst detected by VEGETATION is due to some other phenological indicator. A systematic error of one day in bud-burst translates into a $10 \mathrm{gCm}^{-2}$ year $^{-1}$ error in NPP (about $2 \%$ ). Based on the limited available ground data, any systematic error due to using the VEGETATION data should not lead to significant errors in the calculated carbon flux. In contrast, widely-used methods based on the Normalised Difference Vegetation Index (NDVI) from the AVHRR satellite are likely to confuse snowmelt and vegetation greening, leading to errors of up to 15 days in bud-burst date, with consequent large errors in carbon flux calculations.
\end{abstract}




\section{Introduction}

Vegetation phenology, defined as recurring vegetation cycles (bud-burst, flowering, senescence, dormancy), arises from the strategies evolved by plants to optimize their period of activity under given environmental conditions of temperature, light and water availability. In the boreal zone, it strikes a balance between maximizing annual carbon assimilation and reducing the risk of damage caused by frost. Plants have adapted to their local environment by developing mechanisms based on temperature and/or the photoperiod to detect such optimal conditions ( Sarvas 1972, Sarvas 1974, Hänninen 1991, Heide 1993a, Kramer 1994, Kramer 1995, Hänninen 1995, Kellömaki et al. 1995, Yan and Wallac 1998, Linkosalo et al. 2000, Badeck et al. 2004). The various strategies adopted by different species (differing sensitivities to temperature or to the photoperiod, differing chilling requirements, etc., Heide 1993b) may result in different reactions to climate change. An important question for temperate and boreal ecosystems is whether bud-burst will occur earlier or later in a warmer climate (Hänninen 1991, Kramer 1994, Heide 2003), whose answer depends on the role of chilling. More severe climate change may complicate this question, since current mechanisms may become ill-suited to the new conditions, resulting in selection or adaptation by vegetation (Kramer 1995). Such cases are not considered in the present study, whose approach is applicable only for contemporary climate and moderate climate change.

Vegetation phenology in general, and especially bud-burst and dormancy, have been intensively studied. The main factors governing phenology (air temperature, photoperiod, availability of liquid water) and the conceptual mechanisms (thermal time, chilling requirement, photoperiod requirement) are known, even if the underlying biochemical mechanisms are not well understood. Numerous empirical models have been proposed and applied successfully in various locations for different species (Cannell and Smith 1983, Hänninen 1991, Hunter and Lechowicz 1992, Chuine et al. 1999, Schaber and Badeck 2003). The performances of some of these models have been compared (Chuine et al. 1998, Chuine 2000) with the aim of selecting the correct mechanisms (Chuine et al. 1999). Nonetheless, mechanistic explanations capable of predicting bud-burst are still lacking, so that all current phenology models are semi-empirical and need to be calibrated with external observations.

One source of calibration data is ground observations; these tend to be local and speciesspecific, and their availability is very variable in time and space. However, phenology has been observed from the ground for a long time, in some places for two centuries (Sparks and Carey 1995). Such long-term records are especially useful for detecting changes in the timing of phenology caused by climate change. Particular difficulties arise in obtaining phenology data for the boreal regions, especially Northern Eurasia, which is sparsely populated and poorlyprovided with datasets. However, these regions are of particular interest because the intense climate warming forecast for the end of the twenty-first century (Houghton, 2001) may advance bud-burst dates by two to three weeks and significantly increase the growing season.

New ground-based, species-specific techniques based on pollen traps obtain phenological information from a greater area than local (Spieksma and Nikkels 1998, Chuine et al. 1998). However, for continental and global scales, remote sensing of the Earth by satellites has unique capabilities for obtaining regular, standardised information. Various methodologies have been developed to derive phenology products from satellite sensors such as the Advanced Very High Resolution Radiometer (AVHRR), the Moderate Resolution Imaging Spectroradiometer (MODIS) and SPOT-VEGETATION (VGT) (White et al. 1997, Moulin et al. 1997 , Schwartz 
and Bradley 1999, Zhang et al. 2003). The advantages conferred by these products nonetheless come with some drawbacks compared to traditional observations (Schwartz 1998):

1. Historical data are available only for around the last 20 years, which hinders analysis of trends.

2. Phenology indicators from remote sensing (green-up, maturity, leaf colouring, dormancy) are not directly matched to phenological stages (bud-burst, flowering or senescence). This presents no problem when studying timing changes due to climate change, but is important when attempting to simulate vegetation functioning.

3. The spatial resolution of sensors providing daily global coverage typically ranges between $250 \mathrm{~m}$ and $8 \mathrm{~km}$ (MODIS, VGT, the Medium Resolution Imaging Spectrometer [MERIS] and AVHRR) and the measured signal variations result from the phenological transitions of all the plants within a pixel (Duchemin et al. 1999), as well as, environmental changes, such as snowmelt. In forested areas, the varying budburst dates of species, including the understorey, smooth the observed transition between phenological stages. Phenology derived from satellite data should therefore be considered and used as a broad indicator of vegetation phenology, in contrast to traditional observations that are individual or species-specific (Schwartz 1998, Badeck et al. 2004).

4. Although moderate resolution satellites acquire data from most of the Earth every day, only clear-sky days are usable. Hence, the temporal accuracy of the phenology products depends on temporal patterns of cloudiness during the critical periods; these patterns vary considerably with geographical location.

Nevertheless, satellite datasets have been used to calibrate phenology models at regional (White et al. 1997, Duchemin et al. 1999, Kang et al. 2003) and global scales (Botta et al. 2000, Zhang et al. 2004).

A difficulty in detecting bud-burst and senescence in boreal regions is that the vegetation indices commonly used to derive phenology, the Normalized Difference Vegetation Index (NDVI) and Enhanced Vegetation Index (EVI), are sensitive to the presence of snow. Snowmelt and bud-burst appear very similar in the NDVI and EVI signal, as do snowfall and leaf-fall (Shabanov et al. 2002). However, using the Normalized Difference Water Index defined by Erreur! Source du renvoi introuvable., a new methodology able to distinguish snow from leaves has recently been developed and applied in Siberia (Delbart et al. 2005). This brings significant gains to studies of phenology in the boreal zone.

This paper takes advantage of these new data to calibrate a bud-burst model for the Siberian region. The calibrated model is incorporated into the Sheffield Dynamic Global Vegetation Model (SDGVM) (Woodward et al. 1995, Cramer et al. 2001, Woodward and Lomas 2004), which simulates vegetation growth and cycling of carbon, water and nitrogen. The SDGVM calculates the carbon and water fluxes in the biosphere and is designed for studying global carbon storage and fluxes in the context of $\mathrm{CO}_{2}$ concentration increase and climate change. The phenology model in SDGVM predicts the date of bud-burst (the appearance of the first leaves) and senescence, for all plant functional types. However, this paper restricts its attention to bud-burst in deciduous boreal forests, and does not deal with other vegetation types (evergreen forests, tundra) or the detection of senescence. 
We first calibrate a simple bud-burst model based solely on spring warming. More complex models incorporating a chilling requirement (sequential, parallel, alternating (Chuine et al. 1998) are then investigated, but perform no better than the spring warming model. We, therefore, embed the latter in the SDGVM and study the impact of uncertainties in the budburst date on net primary production (NPP). This work forms part of an overall programme of research aiming to quantify the uncertainties associated with estimates of the terrestrial carbon budget. Therefore, the key questions driving the paper are:

- What accuracy can be achieved by the bud-burst model?

- How does this accuracy affect calculations of the NPP?

\section{Methods}

This study uses a bud-burst dataset derived from VGT (Delbart et al. 2005), ground observations of bud-burst, temperature fields, a land-cover map and a topography dataset. These datasets are briefly summarised below.

\subsection{Bud-burst dataset}

A method to derive bud-burst in boreal regions from optical radiometers is described in detail in Delbart et al. (2005). It is based on the Normalized Difference Water Index (NDWI, Gao 1996), calculated for each pixel as:

$$
N D W I=\frac{M I R-N I R}{M I R+N I R}
$$

where MIR and NIR are the middle and near infrared reflectances. The NDWI is sensitive to the water content of the vegetation or the surface. Since the NDWI decreases during snowmelt and increases during vegetation greening, the bud-burst date is defined as the day on which the NDWI starts to increase after decreasing due to snowmelt. No such clear distinction between snowmelt and bud-burst occurs in the NDVI or EVI time-series commonly used in optical remote sensing.

The method is applied using the VGT S10 product on a region extending from $50^{\circ}$ to $75^{\circ}$ North and $80^{\circ}$ to $120^{\circ}$ East. The S10 product is available since 1998, but excluding 1999 because of technical problems. Since the temperature dataset (see 2.3) ends in August 2002, only the years 1998, 2000, 2001 and 2002 are used in this study. The bud-burst is estimated at $0.1^{\circ}$ grid-spacing by down-sampling the original VGT data from $0.0089^{\circ}$ (about $1 \mathrm{~km}$ ). Figure 1 shows the bud-burst date for 2000 derived from VGT.

Erreur! Source du renvoi introuvable. found a root mean square difference (RMSD) between ground observations and bud-burst derived from VGT that ranged from 6.5 to 9.1 days, depending on the size of the comparison window. There are several potential sources of error, but one important factor is the sampling of the VGT S10 products. Due to cloud cover, the daily measurements of the optical sensor are not all usable, so the S10 product consists of the "best” measurement within a 10-day period. 


\subsection{Ground observations of bud-burst}

Ground observations were provided by the Institute of Botany, Komarov Russian Academy of Sciences, St. Petersburg. They include the dates of bud-burst at nine sites within the region covered by the VGT dataset, for three tree species (birch, aspen and larch). The variations of the bud-burst date in this dataset are explained mainly by the location and inter-annual variations in climate. The bud-burst date differed little between species, so the comparisons described later used only the records for birch, as these are the most complete in the dataset. Over the period 1958-2002 (the period of the temperature dataset, see section 2.3), a total of 192 records are available. Sources of error include subjectivity in the observers' perceptions of the appearance of the first leaf (Badeck et al. 2004) and the representativity of the sampled trees for an entire $0.1^{\circ} \times 0.1^{\circ}$ pixel, but no information is available to quantify such errors.

\subsection{Temperature dataset}

Bud-burst in Siberia depends primarily on the air temperature. Other factors, such as soil moisture, photo-period and water status may be relevant, but are not considered in this study. There are no temperature datasets gridded at the $0.1^{\circ}$ resolution of the VGT-derived phenology dataset, and the finest available spatial resolution for daily mean air temperature is for the ECMWF-ERA40 reanalysis product, at about $1.125^{\circ}$.

This matters, because local climate strongly affects bud-burst. For example, bud-burst observed North-East of Lake Baïkal $\left(54^{\circ} \mathrm{N}, 108^{\circ} \mathrm{E}\right)$ is much later than in the surrounding areas (Figure 1) due to the colder climate in this mountainous area. In the continental cold climate of Siberia, topography is a major factor leading to spatial variations. As a result, areas above 600 $\mathrm{m}$ in altitude were excluded from the calibration, using altitude information from the GTOPO30 global digital elevation model (http://edcdaac.usgs.gov/gtopo30/gtopo30.asp) at a spatial resolution of $0.05^{\circ}$ (but see Discussion in Section 4).

\subsection{Land cover dataset}

Phenology varies considerably between regions, species and even individual plants. Ideally, model calibration should be local and species-specific, but this is not pertinent in the present study because of the coarse spatial scales being considered and the fact that the SDGVM uses plant functional types (deciduous needleleaf, deciduous broadleaf, evergreen needleleaf, C3 grassland, crops, etc.) rather than species information. We consider deciduous forests only and do not distinguish forests with respect to leaf shape, because the ground-based bud-burst observations show no significant differences between larch and broad-leaved deciduous trees ( 0.15 days on average over the 192 records). Evergreens are excluded because their bud-burst is not currently visible in satellite data (the signal is much more sensitive to the deciduous understorey). Modelling cropland phenology is difficult since it depends on the sowing date (Moulin et al. 1998), which is not accurately predictable, but this affects only a small part of the region of interest. The northern tundra will be addressed in a later study.

The Global Land Cover 2000 (GLC2000) (Fritz et al. 2003) is used to demarcate the deciduous forests. GLC2000 is derived from the same VGT sensor as the bud-burst product, which ensures consistency between the two products. Pixels belonging to the deciduous tree classes ("Tree Cover, broadleaved deciduous, open”, “Tree Cover, broadleaved deciduous, closed”, "Tree Cover, needle-leaved deciduous" and "Tree Cover, mixed leaf type") were included; 
these cover $45 \%$ of the area. Figure 2 shows the VGT-derived bud-burst date for 2000, after non-deciduous forests and the pixels higher than $600 \mathrm{~m}$ above sea level were masked out; 33\% of the total area remains. The map shows a clear, smooth north-south gradient with much less variability than in Figure 1.

\subsection{The spring warming model and calibration method}

Most phenology models are based on the concept that a phenological stage is reached once a number of development/forcing units have accrued. The simplest form of these models, the spring warming model (also called the degree-day model since it accumulates values whose unit is ${ }^{\circ} \mathrm{C}$-day), assumes that the ontogenetic development of buds starts when the temperature exceeds some base value, $\theta_{0}$, with higher temperatures increasing the development. Bud-burst begins when the development reaches some value $F^{*}$ (hereafter called the threshold or critical value of rate of forcing). Mathematically, this can be written as:

$$
t_{b b} \text { is the smallest value for which } \sum_{t=t_{0}}^{t_{b b}} \max \left(\theta-\theta_{0}, 0\right) \geq F^{*}
$$

where $t_{b b}$ is the date of bud-burst, $t_{0}$ is the start date ( $1^{\text {st }}$ January), and $\theta$ is the mean daily temperature.

The two parameters, $\theta_{0}$ and $F^{*}$, have to be calibrated using observations. The optimal pair of parameters can be selected by minimizing a cost function, here chosen to be the root mean square difference between VGT-observed bud-burst and the model, defined by:

$$
R M S D=\frac{1}{N} \sqrt{\sum_{x, y}\left(t_{b b}^{E O}(x, y, t)-t_{b b}^{\text {model }}(x, y, t)\right)^{2}}
$$

where $t E O, b b$ is the VGT-derived date of bud-burst, tmodel, $b b$ is the model estimate and the $(x, y$, t) spatio-temporal coordinates run over the $N$ pixels in central Siberia $(N=45000)$; the years of observation are specified in section 3.1. The term root mean squared difference (RMSD) is used rather than root mean squared error since we do not have access to true values of budburst, only three sources of information (model, VGT-derived bud-burst and ground observations) which are not highly accurate.

\subsection{More complex bud-burst models}

More complex phenology models have been developed to account for factors other than spring warming. In particular, for temperate and boreal regions, phenological observations have demonstrated that a period of chilling during the winter may help or is required for bud-burst to occur in spring (Hänninen 1990).

Most models accounting for chilling accumulate a chilling rate, in addition to the forcing rate used in the spring warming model. Three major types of models have been developed, which vary mainly in the way chilling and forcing interact:

- sequential models: The forcing rate only starts to be accumulated once the chilling requirement is reached. 
- parallel models: The chilling and forcing rates are accumulated simultaneously from the beginning of the year but bud-burst occurs only when both sums reach their respective critical values.

- alternating models: Bud-burst occurs when the sum of degree-days reaches a threshold (as in spring warming), but the threshold is a decreasing function of chilling. This approach accounts for the observations that chilling helps but is not required for budburst, and that rapid bud-burst occurs after intense chilling.

The sequential, parallel and alternating models investigated in the present paper are based on the description in Chuine et al. (1998) with slight modifications (Table 1). The models contain three or four parameters, so that full exploration of the parameter space is not computationally realistic. We used instead a simple genetic algorithm to minimize the cost function (Goldberg 1989, Wall 1996). This method is easy to implement and is efficient, avoiding local minima. Other techniques such as simulated annealing may perform equally well (Chuine et al. 1998).

\subsection{The Sheffield Dynamic Global Vegetation Model (SDGVM)}

The SDGVM is a dynamic vegetation model designed to calculate the carbon fluxes and pools in the biosphere at global scale, and especially variations under changing climate (Woodward et al. 1995, Cramer et al. 2001, Woodward and Lomas 2004). Temporal variations of the leaf area index (LAI) provide one fundamental way in which vegetation can adjust to environmental conditions.

In the SDGVM, LAI increase is driven by the stock of carbon accumulated by the plants, while LAI decreases due to leaf mortality. The temporal scheduling is governed by the phenology module (i.e. the LAI is allowed to increase from the bud-burst date, while deciduous species drop their leaves at the senescence date). The bud-burst date depends on both temperature and soil water content, but only the thermal dependence is limiting in Siberia, since spring snowmelt makes water abundant.

The SDGVM incorporates other modules for modeling photosynthesis, evapotranspiration, hydrology, nitrogen cycling, disturbances and soil carbon respiration and storage. Soil temperature, permafrost and frost damage are not currently modelled. In this study, the input variables include:

- Climate data: daily temperature from the ECMWF-ERA40 and monthly precipitation, air humidity and cloudiness from the CRU/UEA dataset (Mitchell et al. 2004). Monthly data are downscaled to a daily time-step with a weather generator developed by Forest Research, UK (Evans et al., 2002), based on an approach similar to that used in other weather generators (e.g. Sharpley and Williams 1990). Precipitation is simulated using a Markov chain and a gamma distribution, while humidity is taken from a Gaussian distribution.

- Soil texture from the International Satellite Land Surface Climatology Project (ISLSCP, http://www.gewex.org/islscp.html).

- Land cover from the Global Land Cover (GLC2000) (Fritz et al. 2003).

A single simulation consists of a spin-up over 900 years to stabilize the various carbon pools, followed by a proper run from 1958 to 2000.

In (Cramer et al. 2001) it is shown that SDGVM provides similar results to other DGVMs, but real validation is difficult because of the lack of suitable datasets, particularly in Siberia. 
Comparison of SDGVM calculations with satellite measurements of biomass in mid-Siberia (Le Toan et al., 2004) suggested that land cover was not well-represented in the model, particularly as regards non-forest types and low-productivity forest. However, the calculations in the present paper use a more up-to-date land cover scheme, and this should not be a source of error in the bud-burst calculations. No strong validation of the carbon flux calculations is currently available (a comment applying to all extant DGVMs).

\section{Results}

\subsection{Spring warming model calibrations}

Five independent calibrations of the spring warming model were carried out, one for each year of observation (1998, 2000, 2001 and 2002) and one for all four years together. Table 2 presents the results. The parameters resulting from all five calibrations are given in the first two rows. The next four rows give the RMSD between the calibrated model and each single year and all years. The last row gives the RMSD between the calibrated model and the ground observations.

After parameter calibration, the bud-burst model differs from the VGT-derived bud-burst with RMSDs ranging from 5.1 to 7.9 days. This is satisfying when compared to the error in the VGT product: from 6.5 to 9.1 days RMSD between the bud-burst date derived from VGT and the ground observations. The variations of RMSD for the different calibrations show that the detection of bud-burst differs between years, with calibration using observations from 2001 leading to the lowest RMSD (between 5.1 and 6.8 days). This suggests that 2001 is less noisy or closer to the ideal behaviour of the spring warming model than other years. Nevertheless, the main feature to note is the calibration with all years, which leads to a RSMD of 6.4 days when compared with all years. RMSD is a broad measure of difference, and includes scatter (described by the standard deviation) and bias. The bias, defined as the difference between the average modelled and average VGT-derived bud-burst dates, is found to be 0.27 days (averaged over the whole year and the full area for the calibration with all years). This means that, on average, the modelled bud-burst date is not significantly earlier or later than the date derived from VGT.

Comparison with the ground observations gives a RMSD ranging between 6.5 and 8.7 days, depending on the calibration year, and 6.9 days for the calibration with all years. This is not much higher than the RMSD with respect to VGT-derived bud-burst. In addition, the bias between the model and the ground observations is about -1.9 days. The fact that the modelled bud-burst occurs earlier than the observed bud-burst at first sight seems surprising, since the ground observations actually measure the first leaf appearance. However, the bias is quite small relative to the RMSD (1.9 compared to 6.9 days), which means that the difference between the model and the observations varies highly in space and time. Therefore, including new years or new phenological stations in the comparison could easily change the value and sign of the bias. In summary, the model is weakly biased with respect to independent ground observations, and the differences from the model are of similar order for both ground observations and the observations used in the calibration (6.9 versus 6.4 days). 
It is interesting to note that, despite the model being calibrated only for recent years when satellite data were available (1998, 2000-2002), it matches past ground-based observations rather well, as illustrated by Figure 3.

All these results are mutually consistent: differences between the model and bud-burst derived from VGT, differences between the bud-burst derived from VGT and the ground observations and differences between the model and the ground observations are all between 6 and 7 days. This suggests that the calibrated model achieves nearly the best possible performance given the data.

Despite this, the optimization of (3) under the minimum RMSD constraint is unsatisfactory as regards biophysical interpretation of the control parameters. This is illustrated by Figure 4, which shows the variation of the cost function (the RMSD between VGT-derived and modelled bud-burst) as a function of the two parameters, $\theta_{0}$ and $F^{*}$, for the all-year calibration. This plot was obtained by calculating the cost function for each $\left(\theta_{0}, F^{*}\right)$ pair. The cost is constant along each curve, and the minimum cost of 6.4 days is marked by $(+)$.

It can be seen that the minimum RMSD occurs within a long, thin, steep-sided valley, along which the RMSD varies only slowly. Although the values of $\theta_{0}$ and $F^{*}$ vary greatly along the floor of the valley, the corresponding changes in bud-burst day are small (it is not obvious that small variations in RMSD correspond to small variations in bud-burst date, but this is true in practice). Hence, large variations in the individual parameter values may occur, depending on the calibration conditions (the dataset, cost function, etc), without significantly affecting the bud-burst date. The calibrations for each single year illustrate this well. Table 2 shows how much the optimal parameters vary, depending on the observation year used for calibration, but Figure 4 reveals that these optimal parameters (marked as triangles) always lie in the valley. Hence, the individual parameter values should not be over-interpreted in biophysical terms, because the spring warming algorithm (1) imposes no biophysical constraints on their allowable values, and it can be seen that strong constraints do not arise naturally in the optimization against observations.

This section demonstrates that a calibrated spring warming model is able to produce accurate estimates of bud-burst. Exact quantification of the error is difficult since true values are not available, but our various results concur at about 6.5 days RMSD.

\subsection{Calibration of more complex bud-burst models}

In this section, we assess whether more complex models perform better than a spring warming model. The characteristics of the different models are given in Table 1.

Table 3 presents the minimum RMSD between each model and the VGT bud-burst after calibrating with the 4 years of VGT data. It is clear that no model performs better than the spring warming model. This may be because the chilling requirement is always fulfilled in Siberia under current conditions (Heide 1993b, Botta et al. 2000). The predictions of the spring warming model may degrade under a future warmer climate, but as long as the chilling requirement is not visible in current observations, the associated process parameters cannot be constrained. The noisiness in bud-burst derived from VGT may also render the calibration procedure insensitive to the chilling mechanism. 
Other advanced models of bud-burst accounting for photoperiod (Heide 1993b, Schaber and Badeck 2003) or soil temperature (Van Wijk et al. 2003) have been developed but not tested in this study. Calibrating models based on both temperature and photoperiod requires both long time series and many locations, because temperature and photoperiod are temporally uncorrelated but spatially (latitudinally) correlated. Our bud-burst dataset spans too few years. Modeling soil temperature (and the frozen/liquid state of water) requires mechanistic modeling of the thermal energy propagation through the canopy and soil (Van Wijk et al. 2003). Such a model includes an extensive set of parameters and requires additional information (e.g. climate), so that calibration using just VGT-derived bud-burst data is beyond the scope of this paper.

In conclusion, the spring warming model is simpler than other phenology models but predicts bud-burst equally well. As a result, it is used in the rest of this study.

\subsection{The impact of uncertainties in bud-burst date on the accuracy of net primary production estimates in Siberian deciduous forests.}

The next sections translate uncertainties in the bud-burst date into uncertainties in the carbon budget of deciduous boreal forests. We focus on the net primary production (NPP), the net carbon assimilated by the vegetation accounting for uptake by photosynthesis and release by vegetation respiration:

$$
\text { NPP }=\text { Photosynthesis }- \text { Vegetation Respiration }
$$

Two distinct sources of uncertainty in the bud-burst data and prediction are possible: noiselike variability and systematic error. Their effects on estimates of NPP are assessed in the next two sections.

\subsubsection{Impact of spatial variability in bud-burst date on carbon flux estimates}

It was shown in section 3.1 that the bud-burst days in the observations and the calibrated model have similar means and an RMSD of about 6.5 days. However, the model values arise from a generalised land surface description and spatially smoothed climate variables, so have less local spatial variability than the observations. Here we assess whether this noise-like difference translates into significant effects on NPP, and whether direct use of observed bud-burst in the SDGVM could provide better accuracy than indirect use of observations through model calibration.

Two simulations were conducted:

- Simulation 1. The phenology model is used from 1958 to 2000.

- Simulation 2. The phenology model is used from 1958 to 1999 and the VGT bud-burst is used in 2000.

The results are summarized in table 4. The table gives the mean NPP in 2000 and the root mean square difference (RMSD) between the two calculations. It can be written:

$$
R M S D=\frac{1}{N} \sqrt{\sum_{x, y}\left(N P P_{1}(x, y)-N P P_{2}(x, y)\right)^{2}}
$$

where $(x, y)$ are spatial coordinates and the model uses a $1^{\circ} \mathrm{x} 1^{\circ}$ grid spacing. The subscripts 1 and 2 refer to the two simulations. 
In 2000, the RMSD between the modelled and observed bud-burst date was 6.5 days. This yields an RMSD for NPP of $41.2 \mathrm{gCm}^{-2} \mathrm{year}^{-1}$ for an average NPP of $572 \mathrm{gCm}^{-2} \mathrm{year}^{-1}$, or an $8 \%$ relative difference. Thus the uncertainty in the VGT data or in the calibrated model has a moderate impact on the NPP. The mean difference of about $28 \mathrm{gCm}^{-2} \mathrm{year}^{-1}$ between the two estimates of NPP is nonetheless significant with respect to the RMSD, despite the bias of the bud-burst model being negligible. This is due to the non-linear response of NPP to bud-burst.

Since the uncertainty in VGT bud-burst observations is independent of the model uncertainty, future estimates of bud-burst could be improved by combining new bud-burst observations and model predictions. For instance, using a Kalman filter (Kalman 1960), the best estimate is the mean of the VGT-derived and modelled bud-burst (as long as they both have the same uncertainty and are not biased) and the theoretical uncertainty on the best estimate is then reduced to $6.5 / \sqrt{2} \approx 4.6$ days.

While available bud-burst observations could replace the phenology module in SDGVM as regards calculations of NPP, this is not the case for full ecosystem modelling, which must be consistent over several years or decades. Using the observations directly, to force the bud-burst dates, or indirectly, by filtering, creates an artificial discontinuity in the phenology process. This disturbs long-term processes (for example, recycling of photosynthetic products by the soil) and may result in artificial fluxes. A meaningful comparison of the type shown in Simulation 2 for the net carbon exchange between the atmosphere and the biosphere would require a long time-series of VGT-derived bud-burst dates. This is not feasible because of the short overlap between the available datasets: the NDWI data from VGT exist for 1998, 2000 and onwards, while the CRU/UEA dataset runs up to 2000 and the ECMWF data until August 2002.

\subsubsection{Impact of systematic errors in bud-burst date on carbon fluxes}

Systematic errors differ from noise in causing a constant (in time) and uniform (in space) shift between the true bud-burst and predicted or observed bud-burst. They may arise in two ways:

1. Bud-burst observations by optical sensors and bud-burst in vegetation models have different meanings. Optical sensors need a substantial amount of greenness (for NDVI) or water content change (for NDWI) in a pixel to detect the bud-burst; in models, budburst is usually meant to signify the day "the first leaf unfolds", although it may be possible to choose a different parameterization more closely matching what sensors measure. Hence, in the absence of calibration, bud-burst derived from optical sensors is likely to occur later than in the vegetation model (but this may depend on how the sensor-based algorithm selects the bud-burst date). The calibration step described above will drive the model to adopt the observed bud-burst date, and this may introduce an error which is systematic in time and space. (The ground observations suggest that any such bias is small, but this conclusion is based on a very limited dataset.)

2. Bias in the temperature dataset may cause bias in the model bud-burst date. Temperature bias is likely to occur only if the temperature datasets used during the calibration and the model calculation differ (this is not the case in the present study). By estimating the average bud-burst date in Siberia for various base temperatures $\left(\theta_{0}\right)$ around the optimal value of $4.1^{\circ} \mathrm{C}$, we found that bud-burst shifts approximately linearly by 3.3 days per ${ }^{\circ} \mathrm{C}$ change in the base temperature. A change in the base temperature is equivalent to a bias in the temperature dataset. 
The consequences of systematic errors in bud-burst on estimates of NPP are illustrated by Figure 5, which shows the calculated annual NPP for deciduous Siberian forests, during the period 1958-2000, as a function of a shift of the bud-burst day with respect to the date predicted by the calibrated model. NPP increases for earlier bud-burst, as expected, since earlier bud-burst increases the length of the growing season, and frost damage is not taken into account in the SDGVM. Accounting for frost damage may reduce the sensitivity of the NPP to the bud-burst date and could result in a function with a maximum turning point rather than a monotonically decreasing function. Nevertheless, the results give an upper limit for the NPP sensitivity.

If bud-burst occurs 1 day earlier, the NPP increases by about $10.1 \mathrm{gCm}^{-2} \mathrm{year}^{-1}$. This corresponds to an increase of $2.2 \%$ in NPP, although 1 day corresponds to a lengthening of the growing season by only $1 \%$. This means that, in the model, the net production in the first days of spring helps vegetation to produce more net production for the whole season. Since the calibrated bud-burst model has a bias of less than 2 days compared to ground observations (see Section 3.1), relatively small systematic errors are therefore expected in the associated calculations of NPP.

For predictions of future behaviour, the sensitivity of the NPP to earlier bud-burst can be interpreted differently. Reducing the base temperature is equivalent to a constant warming during the period before bud-burst. If the temperature increases by $5^{\circ} \mathrm{C}$ (which is on the low side of the forecast range for the boreal regions in the 2050-2100 horizon), bud-burst would move forward by about 16 days $\left(3.3\right.$ days $\left.^{\circ} \mathrm{C}^{-1}\right)$ and NPP would consequently increase by 161 $\mathrm{gCm}^{-2}$ year $^{-1}$, or $34 \%$. Of course, such a rise in temperature would affect all other processes; soil respiration in particular would increase. Nonetheless, these calculations indicate that knowing the size of one of the key components in the net terrestrial flux of carbon requires reliable prediction of bud-burst based on continued observations.

\section{Discussion}

Vegetation phenology is one of the fundamental mechanisms of interaction between climate and vegetation. Global climate change will affect vegetation phenology, with consequences for vegetation functioning and the carbon budget (Hänninen 1991, Kramer 1994, Linkosalo et al. 2000, Heide 2003, Badeck et al. 2004). In turn, climate will be affected by the associated vegetation and soil changes. Phenology is thus both an indicator of climate change and an active player in changes to the Earth system.

This paper addresses the calibration of a bud-burst model at continental scale, the quantification of errors, and the consequences of these errors for estimates of net primary production. We use a bud-burst dataset derived from VGT radiance data by a method able to distinguish bud-burst from snowmelt - a prerequisite for detecting bud-burst in boreal regions.

Spatial variations (the observations range from $50^{\circ} \mathrm{N}$ to $75^{\circ} \mathrm{N}$ ) and temporal variations (4 years of observations) of bud-burst are used to calibrate a two-parameter spring warming model. The calibrated model compares reasonably well with both VGT and ground observations (about 6.5 days RMSD). Accounting for the chilling requirement in more complex models does not reduce the errors. Hence, chilling is not required, the chilling 
requirement is always fulfilled in the area under study, or the bud-burst dataset is insufficiently accurate to show any sensitivity to the chilling effect. If climate change in the region increases the importance of the chilling requirement, the bud-burst model would need suitable modifications. This emphasises the need for continued phenological observations into the future.

The predictions of phenology depend not only on the quality of the phenology derived by VGT, but also on the quality of the related datasets, mainly the temperature and the land-cover. The ECWMF-ERA40 temperature dataset allows successful comparison of a long time-series with the model. This comparison aims at validating the calibrated model, but as a side-effect validates also the temperature dataset. The coarse resolution of the temperature data is, however, a drawback for predictions in mountainous areas, where altitude, and thus temperature, varies rapidly. Although not discussed in this paper, correcting the temperature for altitude variations failed to extend the validity of the model to upland regions. This may be because the VGT dataset is not very accurate in these regions and/or because of particular adaptations of ecosystems to conditions at higher altitudes.

Simulations with the Sheffield Dynamic Global Vegetation Model using the calibrated bud-burst model showed that a 6.5 days RMS error in the bud-burst date corresponds to about $10 \%$ error in the NPP. Given other sources of uncertainties in the carbon budget, there is therefore no pressing need to further improve our estimates of bud-burst date. A key feature of the results presented here is that the bias between the real bud-burst and the observed or predicted bud-bursts is less than 2 days, leading to a relatively small systematic error in NPP. However, they are derived using the NDWI index, which has only been available since the advent of data from the VGT sensor in 1998. Methods based on NDVI can be applied to the much longer AVHRR dataset, but in this case confusion between the date of snowmelt and the date of bud-burst may result in a difference of 15 days or more between the true and derived bud-burst (Delbart et al. 2005). This corresponds to errors in NPP of about 32\%, indicating that calculations based on an NDVI-derived bud-burst date may lead to significant errors in carbon flux estimates.

These results depend on the methodology and vegetation model used in this study, but are sufficiently general to indicate that current errors in the bud-burst date are small enough, in terms of their consequences for the carbon budget, that improved algorithms to detect budburst in central Siberian deciduous forests are not a research priority.

The present study is limited to one region and a short period of time, but its extension in both space and time is desirable. A global phenology model already exists (Botta et al. 2000) but its use of an algorithm based on NDVI is likely to give rise to systematic and significant errors where snow cover is endemic. Extending the bud-burst product based on NDWI to a wider zone in Siberia and to Canada should allow correction of such errors and does not present any conceptual difficulties. The lack of suitable middle infra-red channels in earlier satellite sensors, such as AVHRR, unfortunately prevents the production of an NDWI product and reliable estimation of bud-burst in deciduous boreal forests prior to 1998. Hence, the analysis in this paper cannot be extended back in time to investigate long-term trends. However, extension of bud-burst data forward in time will be possible with current and future space-borne radiometers. Our results suggest that, under moderate climate perturbations, such extra observations may not significantly improve calibration of the model, but using them in a different way (Kalman filtering, for example) may help to reduce uncertainties in the bud-burst date. However, the forecasts of warming in boreal regions are so extreme that associated 
modifications of vegetation behaviour may invalidate current phenology models. Continued observations are, therefore, essential. 


\section{References}

Badeck F, Bondeau A, Böttcher K, Doktor D, Lucht W, Schaber J and Sitch S (2004) Research review. Responses of spring phenology to climate change. New Phytologist, 162(2), 295-309.

Botta A, Viovy N, Ciais P, Friedlingstein P and Monfray P (2000) A global prognostic scheme of leaf onset using satellite data. Global Change Biology, 6(7), 709-725.

Cannell MGR and Smith RI (1983) Thermal time, chill days and prediction of budburst in picea sitchensis. Journal of Applied Ecology, 20, 951-963.

Chuine I (2000) A unified model for budburst of trees. Journal of Theoretical Biology, 207, 337-347.

Chuine I, Cour P and Rousseau DD (1998) Fitting models predicting dates of flowering of temperate-zone trees using simulated annealing. Plant, Cell and Environment, 21(5), 455-466.

Chuine I, Cour P and Rousseau DD (1999) Selecting models to predict the timing of flowering of temperate trees: implications for tree phenology modelling. Plant, Cell and Environment, 22(1), 1-13.

Cramer W et al. (2001) Global response of terrestrial ecosystem structure and function to CO2 and climate change: results from six dynamic global vegetation models. Global Change Biology, 7, 357-373.

Delbart NJ, Kergoat L, Le Toan T, Lhermitte J and Picard G (2005) Determination of phenological dates in boreal regions using Normalized Difference Water Index. Remote Sensing of Environment, 97, 26-38. 
Duchemin B, Goubier J and Courrier G (1999) Monitoring phenological key stages and cycle duration of temperate deciduous forest ecosystems with NOAA/AVHRR data. Remote Sensing of Environment, 67, 68-82.

Evans SP, Randle T and Henshall P (2002) A simplified weather generator model for use in processing modelling of forest system dynamics in the UK. Internal Forest Research report.

Fritz S, Hartley A, Bartholomé E and Belward A (2003) The global land cover for the year 2000, harmonisation, mosaicing and production of the global land cover 2000 database (beta version). URL http://www-gvm.jrc.it/glc2000

Gao BC (1996) NDWI - a normalized difference water index for remote sensing of vegetation liquid water from space Remote Sensing of Environment, 58, 257-266.

Goldberg DE (1989) Genetic Algorithms in Search and Optimization. Addison-Wesley Pub. Co., ISBN 0-201-15767-5.

Hänninen H (1990) Modelling bud dormancy release in trees from cool and temperate regions. Acta Forestalia Fennica, 213, 1-47.

Hänninen H (1991) Does climate warming increase the risk of frost damage in northern trees? Plant, Cell and Environment, 14(5), 449-454.

Hänninen H (1995) Effects of climate change on trees from cool and temperate regions an ecophysiological approach to modeling of bud burst phenology. Canadian Journal of Botany, 73(2), 183-199.

Heide OM (1993) Daylength and thermal time responses of budburst during dormancy release in some northern deciduous trees. Physiologia Plantarum, 88, 531-540. 
Heide OM (1993) Dormancy release in beech buds (fagus sylvatica) requires both chilling and long days. Physiologia Plantarum, 89, 187-191.

Heide OM (2003) High autumn temperature delays spring bud burst in boreal trees, counterbalancing the effect of climate warming. Tree Physiology, 23, 931-936.

Houghton J T, Ding Y, Griggs DJ, Noguer M, van der Linden P J and Xiaosu D (2001) Climate Change 2001: The Scientific Basis Contribution of Working Group I to the Third Assessment Report of the Intergovernmental Panel on Climate Change (IPCC). Cambridge University Press.

Hunter AF and Lechowicz MJ (1992) Predicting the timing of budburst in temperate trees. Journal of Applied Ecology, 29, 597-604.

Kalman RE (1960) A new approach to linear filtering and prediction problems. Transactions of the ASME-Journal of Basic Engineering, 82, D, 35-45.

Kang SY, Running SW, Lim JH, Zhao MS, Park CR and Loehman R (2003) A regional phenology model for detecting onset of greenness in temperate mixed forests, Korea: an application of MODIS leaf area index. Remote Sensing of Environment, 86(2), 337-347.

Kellömaki S, Hänninen H and Kolstrom M (1995) Computations on frost damage to Scots pine under climate warming in boreal conditions. Ecological Applications, 5(1):4252.

Kramer K (1994) A modeling analysis of the effects of climate warming on the probability of spring frost damage to tree species in the Netherlands and Germany. Plant, Cell and Environment, 17(4), 367-377. 
Kramer K (1995) Phenotypic plasticity of the phenology of 7 European tree species in relation to climate warming. Plant, Cell and Environment, 18(2), 93-104.

Le Toan T, Quegan S, Woodward FI, Lomas MR and Delbart N (2004). Radar Remote Sensing of biomass combined with dynamic vegetation modelling to assess carbon budgets of forests, Climate Change, 67, 379-402.

Linkosalo T, Carter TR, Hakkinen R and Hari P (2000) Predicting spring phenology and frost damage risk of Betula spp. under climate warming: a comparison of two models. Tree Physiology, 20(17), 1175-1182.

Mitchell TD, Carter TR, Jones PD, Hulme M and New M (2004) A comprehensive set of high-resolution grids of monthly climate for Europe and the globe: the observed record (1901-2000) and 16 scenarios (2001-2100). Tyndall Centre Working Paper 55. http://www.tyndall.ac.uk/publications/working_papers/wp55_summary.shtml

Moulin S, Kergoat L, Viovy N and Dedieu G (1997) Global-scale assessment of vegetation phenology using NOAA/AVHRR satellite measurements. Journal of Climate, 10(6), 1154-1170.

Moulin S, Bondeau A and Delecolle R (1998) Combining agricultural crop models and satellite observations: from field to regional scales. International Journal of Remote Sensing, 19(6), 1021-1036

Sarvas R (1972) Investigation of the annual cycle of development of forest tree active period. Comminucationes Instituti Forestalis Fennia., 76, 1-110.

Sarvas R (1974) Investigation of the annual cycle of development of forest tree ii. autumn dormancy and winter dormancy. Comminucationes Instituti Forestalis Fenniae, 84, 1-101. 
Schaber J and Badeck FW (2003) Physiology-based phenology models for forest tree species in Germany. International Journal of Biometeorology, 47, 193-201.

Schwartz MD (1998) Green-wave phenology. Nature, 394, 839-840.

Schwartz MD and Bradley CR (1999) Surface phenology and satellite sensor-derived onset of greenness: An initial comparison. International Journal of Remote Sensing, 20 (17), 3451-3457.

Shabanov NV, Zhou L, Knyazikhin Y, Myneni RB, and Tucker CJ (2002) Analysis of interannual changes in northern vegetation activity observed in AVHRR data from 1981 to 1994. IEEE Transactions on Geoscience and Remote Sensing, 40(1), 115130.

Sharpley AN and Williams JR, eds. (1990). EPIC-Erosion Productivity Impact Calculator, 1. model documentation. U.S. Department of Agriculture, Agricultural Research Service, Technical Bulletin 1768

Sparks TH and Carey PD (1995) The responses of species to climate over two centuries: An analysis of the Marsham phenological record, 1736-1947. Journal of Ecology, 83(2), 321-329.

Spieksma FTM and Nikkels AH (1998) Airborne grass pollen in Leiden, the Netherlands: Annual variations and trends in quantities and season starts over 26 years. Aerobiologia, International Journal of Aerobiology, 14, 347-358.

Van Wijk MT, Williams M, Laundre JA and Shaver GR (2003) Interannual variability of plant phenology in tussock tundra: modelling interactions of plant productivity, plant phenology, snowmelt and soil thaw. Global Change Biology, 9(5), 743-758. 
Wall M (1996) GAlib a C++ library of genetic algorithm components. URL http://lancet.mit.edu/ga.

White MA, Thornton PE and Running SW (1997) A continental phenology model for monitoring vegetation responses to interannual climate variability. Global Biogeochemical Cycles, 11(2), 217-234.

Woodward FI and Lomas MR (2004) Vegetation dynamics - simulating responses to climate change. Biological Review, 79(3), 643-670.

Woodward FI, Smith TM and Emanuel WR (1995) A global primary productivity and phytogeography model. Global Biogeochemical Cycles, 9, 471-490.

Yan WK and Wallac DH (1998) Simulation and prediction of plant phenology for five crops based on photoperiod x temperature interaction. Annals of Botany, 81(6), 705716.

Zhang X, Friedl MA, Schaaf CB and Strahler AH (2004) Climate controls on vegetation phenological patterns in northern mid- and high latitudes inferred from MODIS data. Global Change Biology, 10(7), 1133-1145.

Zhang X et al. (2003). Monitoring vegetation phenology using MODIS. Remote Sensing of Environment, 84, 471-475. 


\section{Tables}

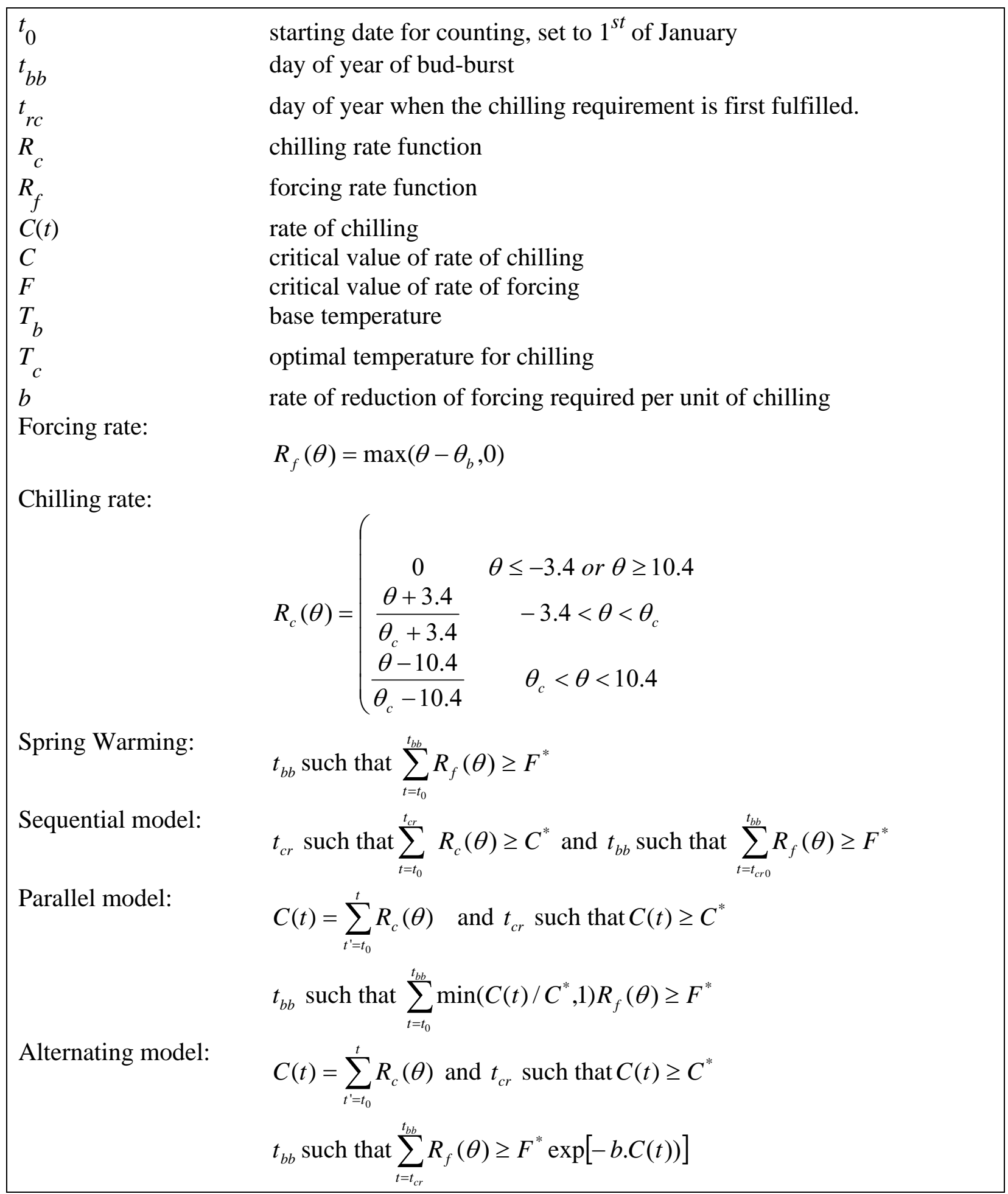

Table 1. Notation and formulation of the major types of phenology model (spring warming, alternating, sequential, parallel) tested in this paper. Some slight variations can be found in the 
literature, but the major mechanisms remain the same. The phenology models are based on formulae in Chuine et al. (1998) with minor simplifications. 


\begin{tabular}{|lccccc|}
\hline Calibration period & 1998 & 2000 & 2001 & 2002 & all years \\
$\theta_{0}\left({ }^{\circ} \mathrm{C}\right)$ & -3.4 & 7.1 & 2.7 & 1.8 & 4.1 \\
$F^{*}\left({ }^{\circ} \mathrm{C}\right.$. day) & 269 & 23 & 95 & 109 & 65 \\
$\begin{array}{l}\text { RMSD in } 1998 \\
\text { (days) }\end{array}$ & 6.6 & 7.5 & 6.9 & 7.9 & 7.0 \\
$\begin{array}{l}\text { RMSD in } 2000 \\
\text { (days) }\end{array}$ & 7.3 & 5.7 & 6.4 & 7.4 & 6.1 \\
$\begin{array}{l}\text { RMSD in 2001 } \\
\text { (days) }\end{array}$ & 5.9 & 5.9 & 5.1 & 6.8 & 5.3 \\
$\begin{array}{l}\text { RMSD in 2002 } \\
\text { (days) }\end{array}$ & 7.0 & 6.6 & 5.3 & 6.8 & 6.9 \\
$\begin{array}{l}\text { RMSD all years } \\
\text { (days) }\end{array}$ & 7.1 & 6.8 & 6.5 & 6.5 & 6.4 \\
$\begin{array}{l}\text { RMSD ground } \\
\text { observations (days) }\end{array}$ & 8.7 & 8.2 & 6.5 & 7.0 & 6.9 \\
\hline
\end{tabular}

Table 2: Results of the spring warming model calibrations. The five calibrations (one for each year and one for all years) are presented in the columns. For each calibration, the first two rows give the optimal parameters, the next five rows show the RMSD with respect to VGT data for each single year and for all the years together, and the last row gives the RMSD with respect to the ground observations. 


\begin{tabular}{|lc|}
\hline & RMSD (day) \\
Spring warming model & 6.4 \\
Sequential model & 6.5 \\
Parallel model & 6.5 \\
Alternating model & 6.4 \\
\hline
\end{tabular}

Table 3: Minimum RMSD obtained for the spring warming model and for models accounting for the chilling requirement. 


\begin{tabular}{|lccc|}
\hline & $\begin{array}{c}\text { Modelled bud- } \\
\text { burst 1901-2000 }\end{array}$ & $\begin{array}{c}\text { Modelled bud-burst 1901- } \\
\text { 1999; VGT-derived bud- } \\
\text { burst in 2000. }\end{array}$ & RMSD \\
NPP in $2000\left(\mathrm{gCm}^{-2} \mathrm{year}^{-1}\right)$ & 572 & 592 & 41.2 \\
\hline
\end{tabular}

Table 4: Comparison of NPP in 2000 for modelled and observed bud-burst dates. RMSD is the root mean square difference averaged over all pixels. 


\section{Figure Legends}

Figure 1: Large-scale and detailed views of VGT-derived bud-burst day in year 2000. The retrieval algorithm detects the first date when the Normalized Difference Water Index (from VGT) increases after having decreased due to snowmelt. The general pattern is a south to north gradient, with earlier bud-burst in the south. Three mountainous areas located in the North, North-East of Lake Baikal and in the South of the zone display later dates.

Figure 2: VGT-derived bud-burst day in year 2000 restricted to deciduous forest pixels (from GLC2000) lower than $600 \mathrm{~m}$ above mean sea level (from GTOPO30).

Figure 3: Comparison at Taseevo $\left(57.2^{\circ} \mathrm{N}, 94.8^{\circ} \mathrm{E}\right)$ between the calibrated spring warming model and ground observations of bud-burst for birch.

Figure 4: The cost function as a function of the two parameters, $\theta_{0}$ and $F^{*}$. Each contour is an equi-cost curve. The cross marks the parameter pair for the all-year calibration; the triangles mark, from right to left, calibration in 1998, 2001, 2002 and 2000.

Figure 5: Calculated mean Net Primary Production (NPP) of the deciduous forests in Siberia for the period 1958-2000, as a function of a shift with respect to the current bud-burst date. A negative value means earlier bud-burst. 


\section{Figures}
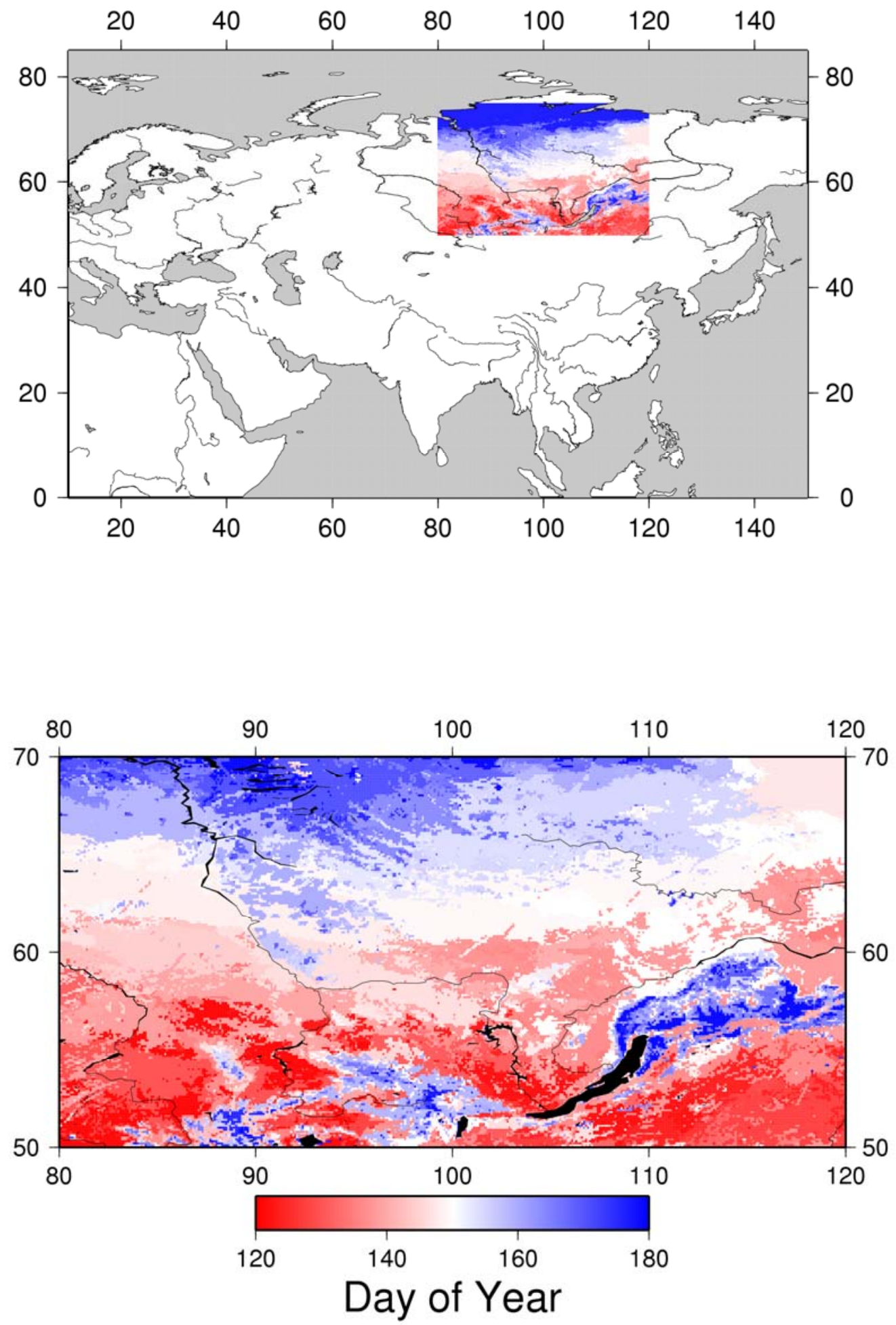

Figure 1 


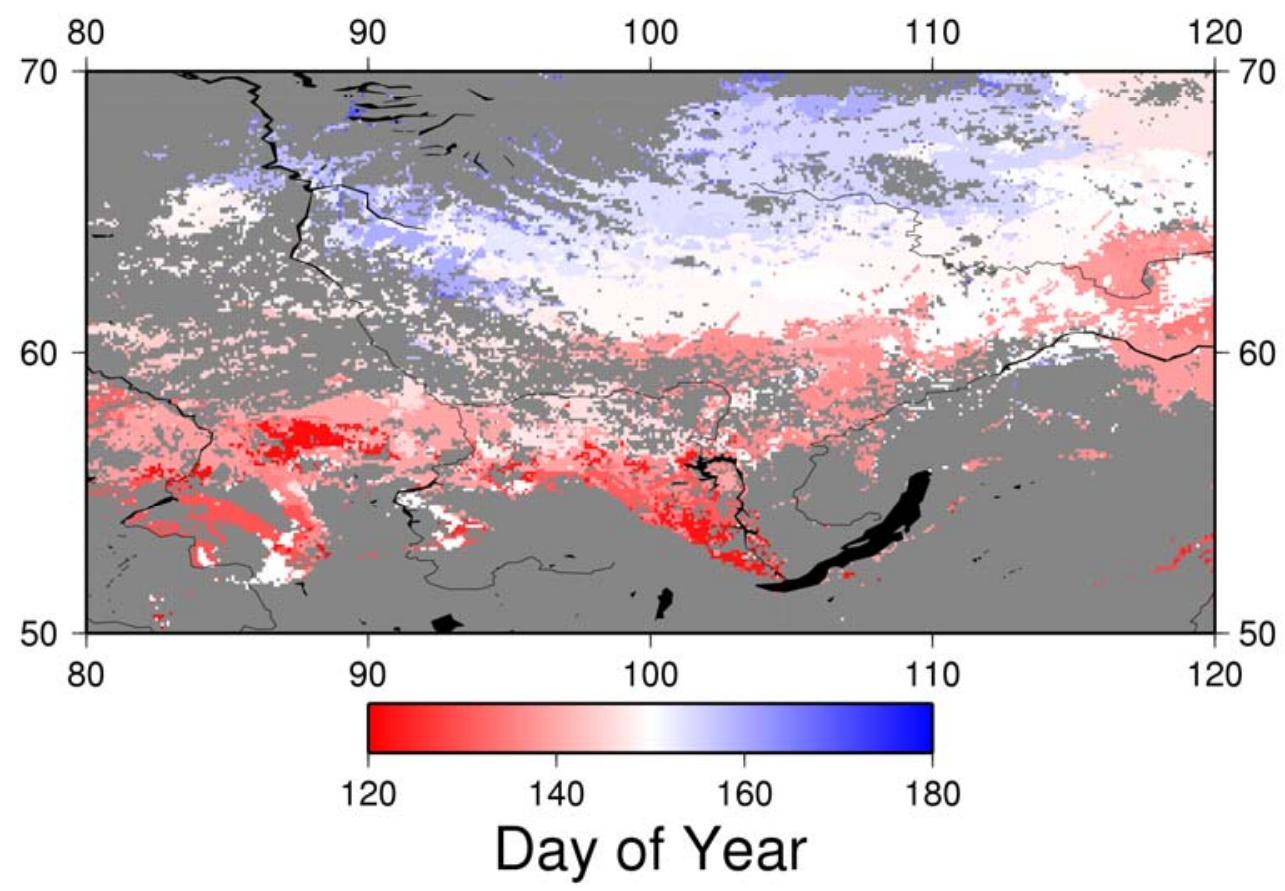

Figure 2 


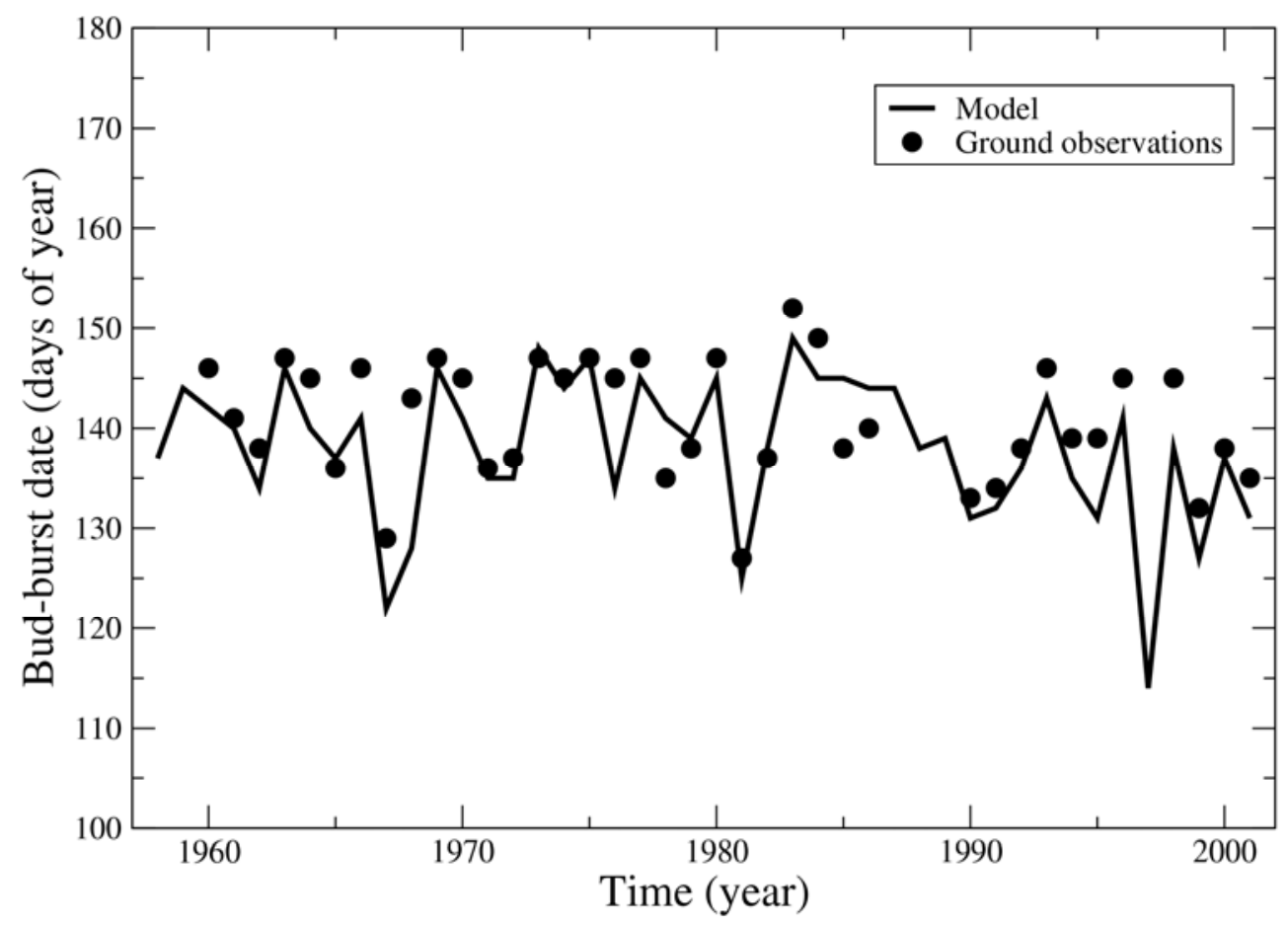

Figure 3. 


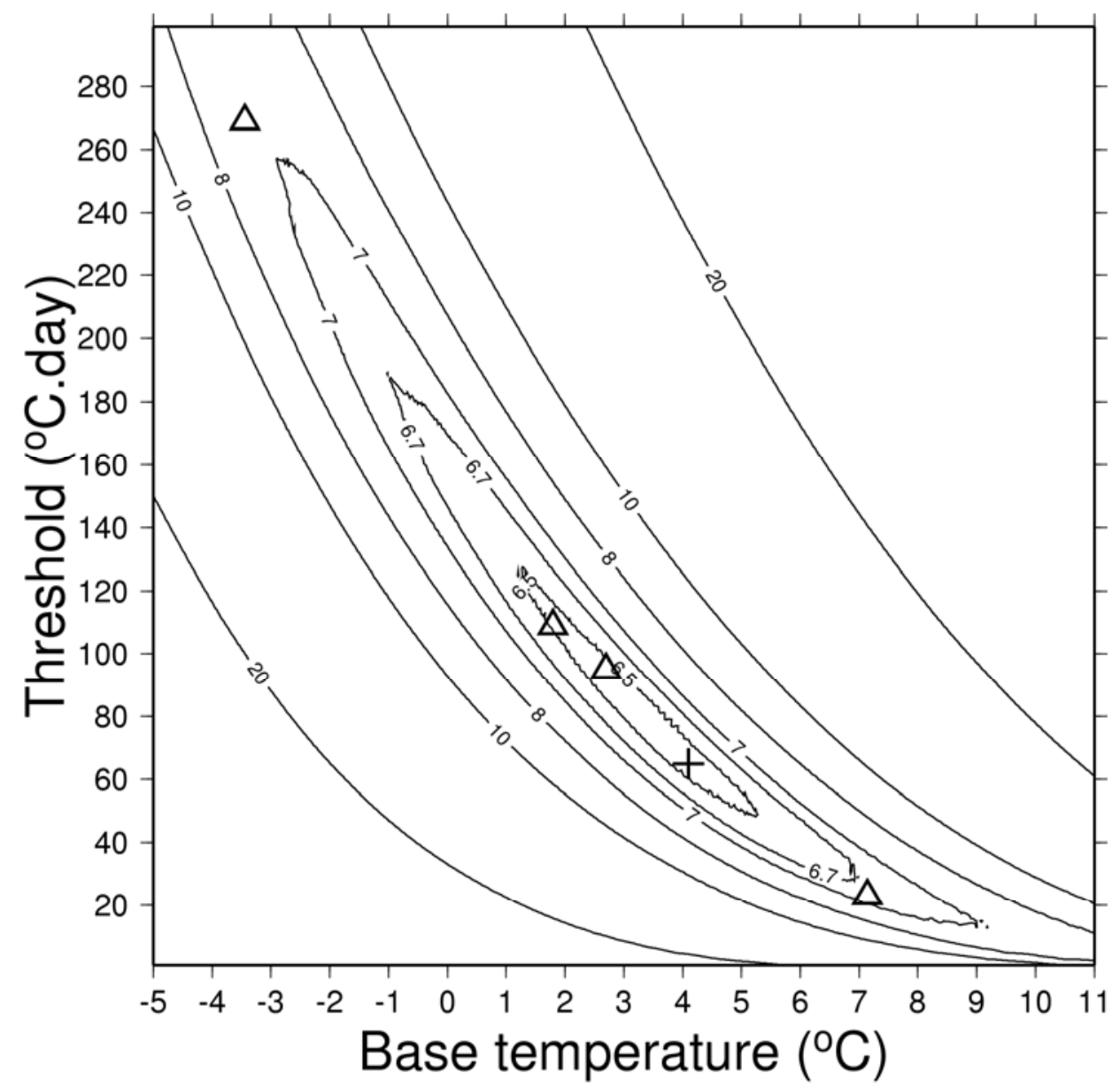

Figure 4. 


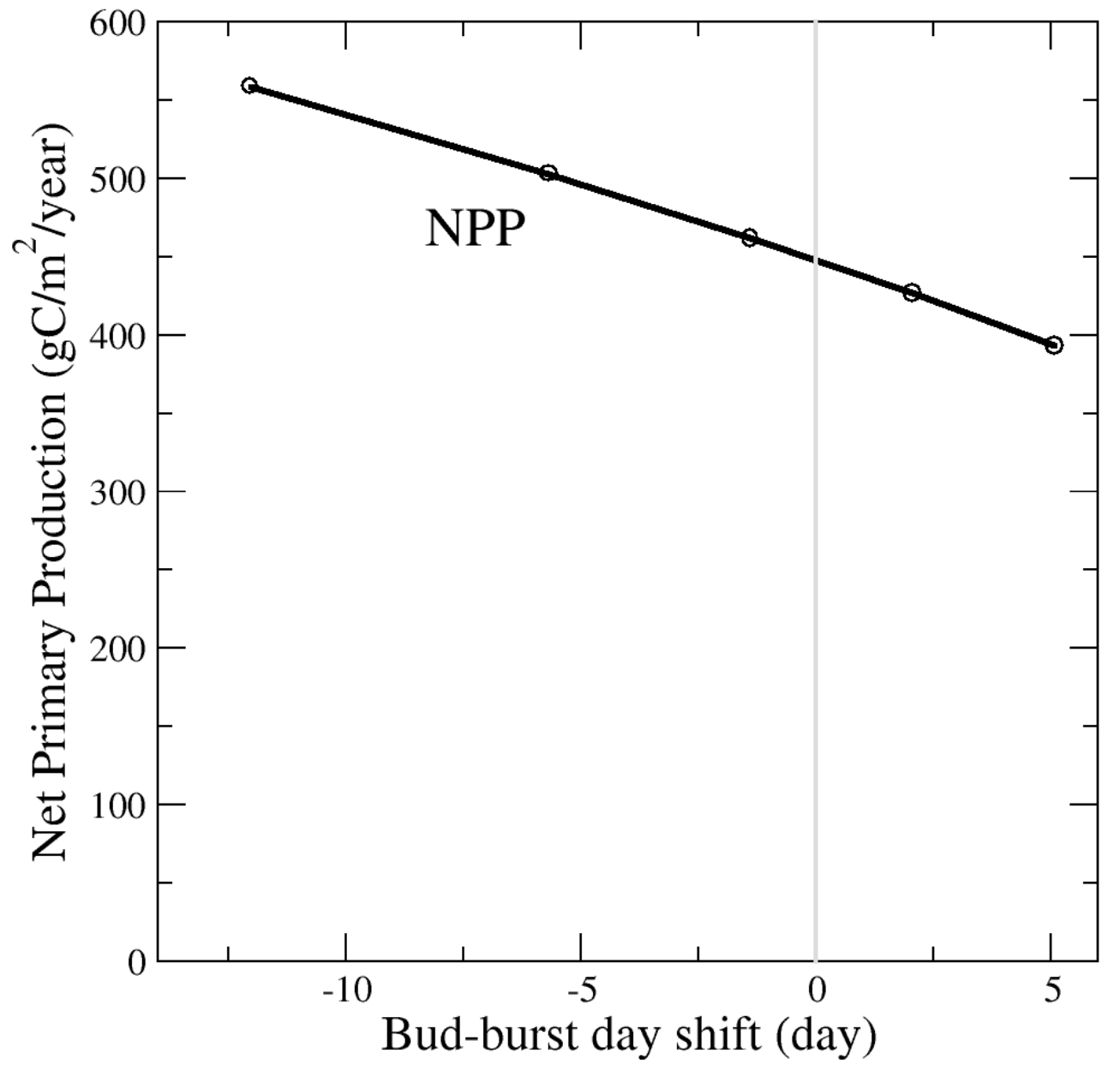

Figure 5. 